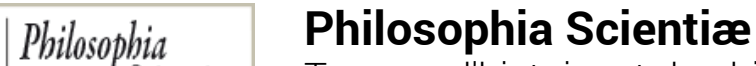

Scientie Travaux d'histoire et de philosophie des sciences

9-2 | 2005

Aperçus philosophiques en logique et en

mathématiques

\title{
Aggregate Theory Versus Set Theory
}

\section{Hartley Slater}

\section{(2) OpenEdition}

Journals

Electronic version

URL: http://journals.openedition.org/philosophiascientiae/530

DOI: $10.4000 /$ philosophiascientiae.530

ISSN: $1775-4283$

Publisher

Éditions Kimé

\section{Printed version}

Date of publication: 1 November 2005

Number of pages: 131-144

ISBN: 2-84174-379-9

ISSN: 1281-2463

Electronic reference

Hartley Slater, "Aggregate Theory Versus Set Theory", Philosophia Scientiæ [Online], 9-2 | 2005, Online since 15 June 2011, connection on 16 January 2021. URL: http://journals.openedition.org/ philosophiascientiae/530 ; DOI: https://doi.org/10.4000/philosophiascientiae.530 


\title{
Aggregate Theory Versus Set Theory*
}

\author{
Hartley Slater \\ Department of Philosophy, UWA, Crawley (Australia)
}

Résumé : Les arguments de Maddy avancés en 1990 contre la théorie des agrégats se trouvent affaiblis par le retournement qu'elle opère en 1997. La présente communication examine cette théorie à la lumière de ce retournement ainsi que des récentes recherches sur les "Nouveaux axiomes pour les mathématiques". Si la théorie des ensembles est la théorie de la partie-tout des singletons, identifier les singletons à leurs membres singuliers ramène la théorie des ensembles à la théorie des agrégats. Toutefois si les singletons ne sont pas identiques à leurs membres singuliers, ce ne sont donc pas des objets extensionnels et ils ne peuvent former une base pour la Science. Dans tous les cas, l'hypothèse d'un continuum n'a aucun intérêt sur le plan physique. Je montre d'abord que, parce qu'il y a des prédicats non-sortaux, la tentative de Frege de faire dériver l'arithmétique de la logique bute dès ses premiers pas. Car il y a des propriétés sans nombre et la contingence de cette condition signifie que la définition du zéro donnée par Frege ne peut s'obtenir à partir de la logique. Ce résultat révèle le besoin de considérer davantage les propriétés sans nombre et donc de générer une théorie des continuums en se basant sur les agrégats méréologiques plutôt que sur des ensembles contenant des nombres de choses.

Abstract : Maddy's 1990 arguments against Aggregate Theory were undermined by the shift in her position in 1997. The present paper considers Aggregate Theory in the light this, and the recent search for 'New Axioms for

*. Portions of this paper are reproduced from 'Aggregate Theory versus Set Theory' Erkenntnis 59(2), 189-202 (2003), with kind permission from Kluwer Academic Publishers.

Philosophia Scientice, 9 (2), 2005, 127-140. 
Mathematics'. If Set Theory is the part-whole theory of singletons, then identifying singletons with their single members collapses Set Theory into Aggregate Theory. But if singletons are not identical to their single members, then they are not extensional objects and so are not a basis for Science. Either way, the Continuum Hypothesis has no physical interest. I first show that, because there are non-sortal predicates, Frege's attempt to derive Arithmetic from Logic stumbles at its very first step. For there are properties without a number, and the contingency of that condition means Frege's definition of zero is not obtainable from Logic. This result then points to the need to consider more fully properties without a number, and so to generate a theory of continua based on mereological aggregates rather than sets containing numbers of things.

1

Ironically, the definition of a set requires it to be a collection of discrete elements, but traditional logic has not incorporated the grammatical difference which distinguishes such elements from others - the difference between count terms and mass terms. The number of things which are $\mathrm{F}$ is indeterminate if ' $\mathrm{F}$ ' is a mass term describing a kind of stuff rather than a count noun describing a kind of individual - maybe something is just martini, rather than a Martini.

As Mary Tiles, amongst the few, has noted, Frege's logical symbolism does not make the discrimination between count and mass terms. It seems to presume, as a result, that the concept of number is applicable to all concepts whatever:

If the concept 'red' fails to determine a unit, there is no way in which the counting of red things can start ...the basis on which Frege applies the concept Number to a concept is that of the existence of a one-one correspondence between the extensions of concepts, and it is just not clear whether, with the framework established by Frege, there could be a one-one correspondence between the class of red things and some other class (the class of blue things, for example). This is because the distinction between concepts which do and concepts which do not determine a unit is not reflected in his formal notation; the notation suggests, but does not assert, that the concept of Number will be applicable to concepts without restriction. ([Tiles 1989, 151], see also [Wright 1983, 2-3], [Dummett 1993, 94]). 
Harry Bunt has studied mass terms more than most, and he has formulated a general theory of 'ensembles', which therefore includes sets merely as a special case. He proves [Bunt 1985, 262] 'A continuous ensemble has no atomic parts ... [it] has no members', adding 'this last result emphasises once again that continuous ensembles are fundamentally different from sets'. He then defined discrete ensembles [Bunt 1985, 263], 'An ensemble is discrete iff it is equal to the merge of its atomic parts', which means that 'Discrete ensembles will be seen to be the antipodes of continuous ensembles, and to be in every respect like ordinary sets'. Continuous ensembles are then subject to the laws of Mereology, while discrete ensembles are handled by the parallel, but abstract, part-whole theory of singletons, as in David Lewis' work [Lewis 1991]. Bunt develops his Set Theory in the Zermelo-Fraenkel manner, however, and so missed the fact that his distinction shows, in a more elementary way than with Zermelo-Fraenkel, how the naive Abstraction Scheme is conditional. Specifically, on his principles, he should say:

iff there are discrete Fs, then $(\exists x)(y)(F y \equiv y \in x)$,

which, amongst other things, relieves difficulties with paradoxical predicates on the right through the possibility of the denial of the stated precondition on the left.

One blindness which has led to several problems in classical Set Theory, therefore, would seem to have involved forgetting that with an amount no number can be specified without an extra parameter - the nomination of a unit. But, incontrovertibly, the point exposes clearly the need just to make formally explicit the definitional presupposition, which allows sets to be formed only when there is a determinate number of discrete elements collected together. Cantor realised this with respect to the number of things in the universe. For if this number was determinate, then, using Cantor's Theorem, we would get Cantor's Paradox. Hence, he argued, there is no set of all things. But the point also shows, more importantly, that Hume's Principle is false. For two null predicates, whose instances can, therefore, be put vacuously into one-one correspondence, even if they have the same power as a result (by the definition of 'power'), do not necessarily have the same number. They may each be numberless.

George Boolos asked [Boolos 1984, 307] 'how do we know that, for every concept, there is such a thing as a number belonging to that concept?' having said [Boolos 1984, 306] 'I want to suggest that [Hume's Principle] is to be likened to "the present king of France is a royal" in that we have no analytic guarantee that for every value of " $\mathrm{F}$ " there is an object that the open definite description "the number belonging to 
F" denotes'. Boolos was alluding to the possibility that 'the number of Fs', in the infinite case, might not have a determinate referent (and see [Tiles 1989, 63, 151]), but he never doubted that the absence of a referent might arise in the other crucial case, at the other end of the numerical spectrum. Somewhat similarly the same can be said about Wright. Although Wright has been amongst the few to separate out sortal concepts, and specifically exclude, with Tiles, as above, colour adjectives from this class, he has never voiced any suspicion that the conflation of sortal and non-sortal concepts, recognisably present in Frege's Logic, had any repercussions for Frege's handling of Arithmetic. Boolos and Wright, with others, have demonstrated how most of Frege's development of Arithmetic can be obtained from Hume's Principle, starting from Frege's definition of zero as the number of things which are not self-identical $(\mathrm{Nx}: \mathrm{x} \neq \mathrm{x})$. But in this extensive, and now very elaborate discussion, no question has been raised about whether

$$
\neg(\exists \mathrm{x})(\mathrm{x} \neq \mathrm{x}),
$$

entails

$$
\mathrm{Nx}: \mathrm{x} \neq \mathrm{x}=0 .
$$

If the negative existence statement entails the numerical statement, then it entails

$$
(\exists \mathrm{n})(\mathrm{Nx}: \mathrm{x} \neq \mathrm{x}=\mathrm{n}),
$$

and that is contingent on ' $\mathrm{x} \neq \mathrm{x}$ ' being a sortal predicate. But what unit is determined by non-self-identity? Indeed, how are sortal concepts to be defined? Much ink has been spilled debating whether Hume's Principle is analytic, and so whether the Arithmetic taken to be derivable from it can, or cannot, be properly described as a part of Logic. But if Logic does not discriminate between sortal and non-sortal concepts, then there is no way to get from it the other crucial element in Frege's generation of the number series: its starting point.

We say 'the number of Fs is n' and can do so whether $\mathrm{n}$ is $0,1,2$, or more; but only count nouns pluralise in the appropriate way. Mass terms sometimes appear pluralised, but not in the same sense: in 'there are several champagnes', for instance, we are speaking about glasses of champagne, maybe, or varieties of champagne. In English we can say 'it is F' rather than 'it is an F', but nothing corresponding to this is to be found in Frege's language. Maybe there is no martini in a glass. Does that mean the number of martini in the glass is zero? It does not. There is no such thing as a number, i.e. a number of Fs, in this case. There might have been some F, rather than no F, and in both cases as much $\mathrm{F}$ as $\mathrm{G}$, but the required plural case, and so the possibility of a 
number, and the same number, just does not arise. If ' $\mathrm{F}$ ' is a mass term, then ' $(\exists \mathrm{x}) \mathrm{Fx}$ ' and ' $\neg(\exists \mathrm{x}) \mathrm{Fx}$ ' simply read 'there is some $\mathrm{F}$ ' and 'there is no $\mathrm{F}$ ', and even ' $(\exists \mathrm{x})(\mathrm{Fx} .(\exists \mathrm{y})(\mathrm{Fy} . \mathrm{y} \neq \mathrm{x}))$ merely reads 'there is some $\mathrm{F}$, and some more $\mathrm{F}$ '. In none of these cases, therefore, do numbers or pluralisation enter the content. Could we not simply introduce a count term, and talk about the number of Cs which are F, or, more generally, the number of things which are F instead? Wright admits [Wright 1983, $3]$ 'to number the instances of some non-sortal concept is intelligible only if relativised to a sortal' (see also [Hale \& Wright 2001, 315, 386, 415]). Certainly if there is no gold then the number of ingots which are gold is zero; indeed, the number of things of any sort which are gold is zero. But the necessary distinction between substantives and adjectives is just what is lacking. Maybe

$$
\neg(\exists \mathrm{x}) \mathrm{Fx},
$$

is equivalent to

$$
\text { (C) }(\mathrm{Nx}:(\mathrm{Cx} . \mathrm{Fx})=0) \text {, }
$$

where ' $\mathrm{C}$ ' ranges over count terms, but one cannot say this in Frege's concept-script.

\section{2}

So we are led to construct in more detail a theory of continua based on mass terms, and thereby criticisms of traditional theories of continua based on count terms.

Ever since Gödel's and Cohen's independence results, showing the Continuum Hypothesis $(\mathrm{CH})$ was neither provable nor disprovable in classical Set Theory, the question has been asked whether some new axioms are needed to add to that theory [Fraenkel 1965, 426]. Several books have been devoted to the question (for example [Tiles 1989], [Maddy 1990a], [Maddy 1997]), and now it has reappeared, at a major ASL Conference, in the even more ambitious form 'Does Mathematics need New Axioms?' The more general expectation that it is Mathematics, and not just Set Theory which is in want of new axioms, shows many still think Set Theory has some more privileged, foundational place, such that all Mathematics can, or at least ought to be definable within it.

But there is a part of Mathematics which cannot have a set-theoretic base. Moreover, it is a part of Mathematics which is crucial to Science, since it deals with physical quantities themselves. The attempt to treat physical quantities by means of traditional Set Theory has led to 
mistaken views of continua, and, in particular, to views of continua as infinite collections of points, or infinitesimal units. Removing that idea directly leads to undermining the outlook which sees $\mathrm{CH}$ as a problem to do with continua, since if there is no number of points in some stuff then there is no question of whether that number is, or is not greater than some other.

Penelope Maddy is a leading philosopher still expecting a decision on CH. This opinion was once helped along with a Gödel-like, even if physicalised, Platonism, although she now agrees that 'Platonism cannot justify the practice of Set Theory, in particular the practice of seeking new axioms to settle the CH' [Maddy 2000, 415]. But Platonism, in some form, was surely operative in keeping the worry over $\mathrm{CH}$ alive. There are plenty of results in pure mathematics about set theories both with and without $\mathrm{CH}$, as there are about set theories both with and without the Axiom of Choice, or the Axiom of Foundation, for instance. And that not only cancels the enlargement of the worry into a supposed worry over Mathematics as a whole, it also shows that any worry over $\mathrm{CH}$, and the like, stems from some other, non-mathematical source. Thus Platonists have the idea that there is some utterly fundamental reality, full of sets, which it is the proper job of, at least, Set Theory to correctly describe.

Certainly there is physical reality to correctly describe, and thereby possible new axioms for applied mathematics. Maddy once defended classical Set Theory on the grounds of its indispensability to science, even though she appreciated it has a strong competitor in any claim for scientific respectability, in the more nominalistic Aggregate Theory ([Maddy 1990a, 60], [Maddy 1990b, 276]). But, as we shall see, her grounds for the comparative worth of Set Theory over Aggregate Theory were surprisingly flimsy, and it is in Aggregate Theory that some variant new axioms for applied mathematics are to be found.

Maddy, for one thing, thought that there would inevitably be logical difficulties with this kind of theory. For, if it deals just with individuals and properties, then it is seemingly faced with the Paradox of Predication [Maddy 1990a, 62]. And that indeed might be a problem (though one, apparently, which can be met, see [Slater 2000]), if there weren't a line more in tune with Physicalism, as will be explained below, which replaces properties with plural predication over individuals instead. But Maddy's main grounds for preferring Set Theory lay in its concordance, as she saw it, with modern science. Set Theory specifically won out through the need for sets of non-denumerable rank. The 'simpler' Aggregate Theory [Kessler 1980], [Simons 1982] might account for what would otherwise be finite sets of discrete things, but it could not handle 
continuous phenomena, she said [Maddy 1990a, 63]. The most obvious thing which strikes one as flimsy about this claim is that while the physical theories which were prevalent around the time when Set Theory first got its foothold did embrace continuous phenomena in the sense Maddy understands them, it is characteristic of the theories more fully developed in the twentieth century - notably Quantum Theory, and various Atomic Theories - that this is questioned. And Maddy has now herself realised how shaky, in this way, the observational ground was on which she once staked her theory [Maddy 1997, II.6, especially page 152].

However, as we have seen, there are other recent developments, specifically in the theory of what might still be called 'continuous phenomena', which Maddy also did not consider. The distinction between mass and count terms has not been available in standard Predicate Logic, and it is now realised that this has led to, or, at least has been a central part of, the professional expectation that the theory of number, and hence the theory of sets, is involved in the explanation of all phenomena ([Wright 1983, 2-3], [Tiles 1989, 151]). Certainly some mass quantities involve manifolds with atomic elements whose parts are not counted as the stuff itself, and these, therefore, do not involve numbers of 'higher ranks', since they have a finite structure. But all that means is that, if there is a theoretical advantage to Set Theory, on the basis of any of Maddy's arguments, the focus must be on how to handle ensembles of non-discrete elements, in Bunt's terms. It would seem that Mereology is the right basis for an understanding of them, however, since I shall show now that there is indeed no difficulty for the developed form of Mereology which is Maddy's main opposition, in connection with them.

\section{3}

How does Aggregate Theory formalise these matters? It is convenient, first of all, to draw the count-mass distinction for physical properties using the mereological relation 'proper part of' (' $<$ '). Then ' $\mathrm{P}$ ' is a mass term if and only if it is possible that

$$
(\exists \mathrm{x})(\exists \mathrm{y})(\mathrm{x}<\mathrm{y} \cdot \mathrm{Px} . \mathrm{Py}),
$$

while ' $\mathrm{P}$ ' is a count term if and only if it is necessary that

$$
(\mathrm{x})(\mathrm{y})(\mathrm{x}<\mathrm{y} \supset \neg(\text { Px.Py })) .
$$

In English we distinguish the two cases saying ' $\mathrm{x}$ is $\mathrm{P}$ ', and ' $\mathrm{x}$ is a $\mathrm{P}$ '; here I shall write ' $\mathrm{P}^{\text {' }} \mathrm{x}$ ' and ' $\mathrm{P}^{*} \mathrm{x}$ ', instead. One might try to go on to form sets for each ' $\mathrm{P}^{*}$ ' on the basis of an Abstraction Axiom: 
$(\exists y)(x)\left(P^{*} x \equiv x \in y\right)$

But the two quantifiers would either have to range over separate intensional and extensional domains, to escape in an obvious way the problem with Russell-type paradoxes, or both over both domains, in which case there would again be no paradox, for the more elusive reason that a contradiction arising with a given predicate would merely show that the predicate in question was not count, i.e. could not be substituted for ' $\mathrm{P}$ '. It is more in tune with Physicalism, however, to remove the reference to sets, as above, and take the ' $\mathrm{y}$ ' in the more inclusive

$$
(\exists \mathrm{y})(\mathrm{x})(\mathrm{Px} \equiv \mathrm{x} \in \mathrm{y})
$$

to be a plural variable, which prevents Russellian paradoxes in much the first way - through the impossibility of substitution of ' $y$ ' for ' $x$ ' [Boolos 1984].

Quine, of course, thought of himself as a Physicalist, not appreciating the intensional nature of his sets, but he still was careful to first show how far Set Theory can go without taking set abstraction terms to be singularly referential [Quine 1963]. He should have remembered that in place of, for instance, 'the number of the set of apples is 3' we say just 'the number of the apples is 3'. For the consequent incorporation of irreducible plurals into our language is just what allows the totality of the apples to be a physical object. Indeed the mereological sum of the apples is then the only relevant single individual associated with all of them. Frege knew [Frege 1968 28-9] that some cardboard could be considered a single deck of cards, or four suits, or fifty two cards, but thought that the numbers $1,4,52$ therefore attached to single objects different from the cardboard. The cardboard contains all the objects there are, however, and seeing the totality of any of them is not seeing some further object, any more than seeing Oxford University was seeing something further beyond seeing all the Oxford Colleges, in Ryle's classic example of a category mistake [Ryle 1973, Ch 1].

Clearly we can count other things besides physical objects, and in those cases there is no mereological sum of the things involved: but then there is no set either, there is merely a number of things. John Mayberry was misled at this point. He thought that whenever there was a number of things there was a set, since, in fact, that number of things was the set. He said [Mayberry 2000, 35, see also 21]: "according to Webster, a herd is 'a number of animals of one kind, kept together under human control', and according to Dr. Johnson a herd is a number of beasts together"'. In connection with this, Mayberry has essayed a 'Euclidean Set Theory', which embraces many appropriately finitist conclusions. But while there may be a number of beasts in a herd, so that the herd consists in that 
number of beasts, still the number of beasts is not the herd, since that would make the number a spatio-temporal object. The separation allows there to be numbers of things when there are no totalities of them: there is no object, for instance, which consists in a number of properties, there are merely those properties.

The grammar of number words ensures this, principally because the number of things of a certain kind is to be analysed quantificationally. So number words have a different place from object words. Thus we know, for instance (c.f. [Bostock 1974]), that, if a count noun is involved,

$(0 \mathrm{x}) \mathrm{Sx} \equiv \neg(\exists \mathrm{x}) \mathrm{Sx}$,

$(1 \mathrm{x}) \mathrm{Sx} \equiv(\exists \mathrm{x})(\mathrm{y})(\mathrm{Sy} \equiv \mathrm{y}=\mathrm{x})$,

and thereafter, quite generally, since pluralisation is guaranteed:

$(2 \mathrm{x}) \mathrm{Sx} \equiv(\exists \mathrm{x})(\mathrm{Sx} .(1 \mathrm{z})(\mathrm{Sz} . \mathrm{z} \neq \mathrm{x}))$,

$(3 \mathrm{x}) \mathrm{Sx} \equiv(\exists \mathrm{x})(\mathrm{Sx} .(2 \mathrm{z})(\mathrm{Sz} . \mathrm{z} \neq \mathrm{x}))$, etc..

But also, we can always index a non-zero number of things using ordinal numbers. For example, given that there is a positive number of S's we can say

$$
(\exists \mathrm{n})(\mathrm{y})\left(\mathrm{Sy} \equiv(\exists \mathrm{z})\left(\mathrm{z} \leq \mathrm{n} \cdot \mathrm{y}=\mathrm{s}_{z}\right)\right),
$$

and the well ordering of the Ss is straightforwardly achieved by using epsilon terms. Thus ' $\epsilon \mathrm{xSx}$ ' can be taken to be 'the first $\mathrm{S}$ ' (see [Leisenring 1969]), and so ' $\epsilon \mathrm{x}(\mathrm{Sx} . \mathrm{x} \neq \epsilon \mathrm{ySy})$ ' can be taken to be 'the second S', etc. In full, we can write

$$
\begin{aligned}
& \epsilon_{1} \mathrm{xSx}=\epsilon \mathrm{xSx}, \\
& \epsilon_{m+1} \mathrm{xSx}=\epsilon \mathrm{x}\left(\mathrm{Sx} .(\mathrm{y})\left(\mathrm{y} \leq \mathrm{m} \supset \mathrm{x} \neq \epsilon_{y} \mathrm{zSz}\right)\right) .
\end{aligned}
$$

If there are $n$ Ss, i.e. ( $\mathrm{nx}) \mathrm{Sx}$, then the first $\mathrm{n}$ of these epsilon terms will all have distinct referents amongst the Ss, and we can take

$$
\mathrm{s}_{z}=\epsilon_{z} \mathrm{xSx} \text {. }
$$

The reason why we have to specify the total number is because there is no guarantee, with respect to the epsilon terms above that ordinal number, that they have distinct referents - or indeed refer to an S.

It is the right hand side of the above equivalence which then says that the item in question is one of a number of things, and so it shows that the expression 'is one of a number of Ss' is not a simple relation between two objects, as in

$$
\mathrm{y} \in \mathrm{s} \text {, }
$$

but a complex expression with parts

$$
(\exists \mathrm{z})(\mathrm{z} \leq \mathrm{n} .
$$

i.e. 'is one of a number', and 


$$
\left.\mathrm{y}=\mathrm{s}_{z}\right),
$$

i.e. 'of Ss'. A representation of it as ' $y \in s$ ' requires ' $s$ ' to be a plural term.

The number of $\mathrm{P}^{*} \mathrm{~s}$ in a mereological totality, by contrast, is definable via

$$
\begin{aligned}
& 1\left(\mathrm{x}, \mathrm{P}^{*}\right) \equiv \mathrm{P}^{*} \mathrm{x} \\
& \mathrm{n}+1\left(\mathrm{x}, \mathrm{P}^{*}\right) \equiv(\exists \mathrm{y})\left(\mathrm{y}<\mathrm{x} . \mathrm{n}\left(\mathrm{y}, \mathrm{P}^{*}\right) \cdot 1\left(\mathrm{x}-\mathrm{y}, \mathrm{P}^{*}\right)\right) .
\end{aligned}
$$

A species-specific collective noun ' $\mathrm{C}^{*}$ ' is then just one for which there is an associated count noun ' $\mathrm{D}^{*}$ ' such that

$$
\mathrm{C}^{*} \mathrm{x} \equiv(\exists \mathrm{n}) \mathrm{n}+1\left(\mathrm{x}, \mathrm{D}^{*}\right) \text {. }
$$

A non-species-specific collective noun, like 'set', can then be defined via quantification over $\mathrm{D}^{*}$. Sets, on this basis, must have at least two members - there is no point in using a collective noun if there is only one count item involved, since the straight description of that, as $\mathrm{D}^{*}$, then serves to characterise it completely. Also if a collective noun applies then the set is obviously not empty. These features of sets were noted by Black in his ground-breaking study of 'the elusiveness of sets' [Black 1970]; but now his sets are less elusive, they have been captured in a clear formalism. One can, of course, easily still show Cantor's Theorem, for instance, though in the form: the number of things which consist in some $\mathrm{P}^{*} \mathrm{~s}$ is 2 to the power of the number of $\mathrm{P}^{*} \mathrm{~s}$ (minus 1, though, since there are now no null sets.).

\section{4}

What complements this basis for straight rivalry with Set Theory, however, is a further, distinct theory of mass terms, whether these involve atoms, as when

$$
(\exists \mathrm{x})\left(\mathrm{P}^{\mathrm{c}} \mathrm{x} .(\mathrm{y})\left(\mathrm{y}<\mathrm{x} \supset \neg \mathrm{P}^{\mathrm{c}} \mathrm{x}\right)\right),
$$

or are homogeneous, i.e.

$$
(\mathrm{x})\left(\mathrm{P}^{\prime} \mathrm{x} \supset(\exists \mathrm{y})\left(\mathrm{y}<\mathrm{x} \cdot \mathrm{P}^{6} \mathrm{y}\right)\right) .
$$

Remembering the finiteness of the mereological, i.e. physical universe, we can then say,

$$
(\exists \mathrm{x}) \mathrm{P}^{\prime} \mathrm{x} \supset(\exists \mathrm{y})(\mathrm{x})\left(\mathrm{P}^{\prime} \mathrm{x} \equiv \mathrm{x}<\mathrm{y} \text { v } \mathrm{x}=\mathrm{y}\right) .
$$

With respect to these quantities we can, as a result, apply notions of amount based on fractions of a whole - or, more practically, comparison with arbitrary finite paradigms, like standard metres, and clocks [Bostock 1979]. Such a development of the theory of proportion is the 
everyday basis for more sophisticated finitary notions of measure (see below). In the first case, if the atoms are the same size, the proportions are guaranteed to be rational, in the latter case that is not so. But in the latter case, the crucial point, as we shall see, is that we do not need to find 'irrational numbers' since we have analogue Geometry instead.

What is it, according to Maddy, that the Aggregate Theorist specifically cannot do? Maddy expected her to introduce measures [Maddy 1990a, 167], but also to 'explain the behaviour of Borel regions', and the like - the hierarchy of sets formed from sets of real points and their successive accumulation points. The behaviour she mentioned was that many such sets are 'determined', and Martin's theorem proving this involves an inescapable commitment to sets of infinite rank, as Friedman has shown [Maddy 1990a, 166]. One problem the Aggregate Theorist seemingly faces, therefore, is that Mereology, as above, puts a block on actual denumerable infinities. An infinite number of metres would have to be, impossibly, the same length even if we cut a metre off it. But that still leaves potential denumerable infinities, which is sufficient to match all that Analysis, Set Theory, and Formal Logic can do, as a number of recent writers have shown. Through Mycielski's work, in particular [Mycielski 1981], we see how more sophisticated notions of measure can be introduced without requiring any actual infinity. Through the application of Mycielski's work which Lavine has developed [Lavine 1994], finitary models of anything set theorists can generate become available (though Lavine tries to use them to the reverse effect, i.e. to induce an understanding of infinity). Hailperin shows that '[Herbrand's] Fundamental Theorem ... provides a characterisation of syntactic adequacy of a formal system of first-order logic ... and an understanding of 'true in an infinite domain', both conformable with a non-infinitistic point of view; that is, he has replacements for Gödel incompleteness and LöwenheimSkolem satisfiability (in an infinite domain) which do not presuppose the actual infinite' [Hailperin 1992, 72-3].

One further problem the Aggregate Theorist faces, it might therefore seem, concerns irrational numbers, since without completed infinities they cannot be defined. But the diagonal of a unit square, for instance, is still there, in the appropriate aggregate, even if there is no number to directly measure it. Bostock shows 'how the study of continuous quantities could proceed without assuming the existence of irrational numbers, for classical Greek geometry was of course pursued without this assumption' [Bostock 1979, 211]. These 'continuous quantities', however, are not those studied by Dedekind, and Cantor, which Maddy senses are no longer required by Science. They are not infinite sets of infinitesimal 
points, but simply amounts of stuff, i.e. finite multiples of arbitrarily chosen, but still finite units. So continua are numerically measured by indefinite numbers, not infinite numbers.

The fundamental point is that, since the Aggregate Theorist is handling at first hand the physical actualities which Science has to deal with, then there is an indispensability about her theory which Maddy now recognises is lacking with Set Theory. Allowing the Aggregate Theorist some analogue Geometry to augment her digital Arithmetic doesn't cover Borel regions, admittedly (c.f. [Bostock 1979, 225]), but does that deter her? Being concerned with the science of physical quantities rather than the metaphysics of real numbers, she has no urge to explain any of the strange behaviour of point sets, because Ockham, if not the recent progress of Science, has showed her there is no need to do so. The Aggregate Theorist is more impressed for a start with Aristotle, who believed that real points cannot be reached from physical reality, and the constructivists, who believed, likewise, that a continuum is never numerically resolved [Maddy 1997, 17, 92]. Above all she agrees with Wittgenstein [Rodych 2000, 286, 288]: 'there is no such thing as an infinite set in extension, but only the signs which we actually operate', 'an irrational number isn't the extension of an infinite decimal fraction ... it is a law which yields extensions', 'the concepts of infinite decimals in mathematical propositions are not concepts of series, but of the unlimited technique of expansion of series'.

\section{References}

BLACK, M.

1970 The Elusiveness of Sets, Review of Metaphysics, XXIV (1) 614636.

Boolos, G.

1984 To be is to be the value of a variable (or to be some values of some variables), Journal of Philosophy, LXXXI, 430-449.

Bostock, D.

1974 Logic and Arithmetic, volume I., Oxford: O.U.P.

Bostock, D.

1979 Logic and Arithmetic, volume II., Oxford: O.U.P. 
Bunt, H.C.

1985 Mass Terms and Model-Theoretical Semantics, Cambridge: C.U.P.

Dummetт, M.

1993 Frege: Philosophy of Mathematics, London: Duckworth.

Fraenkel, A.A.

1965 Set Theory, in Edwards, P. (ed.), Encyclopedia of Philosophy, New York: Macmillan.

FreGe, G.

1968 The Foundations of Arithmetic, $2^{\text {nd }}$ edition, Oxford: Blackwell. HAILPERIN, T.

1992 Herbrand Semantics, the Potential Infinite, and Ontology-Free Logic, History and Philosophy of Logic, 13, 69-90.

Hale, B. \& Wright, C.

2001 The Reason's Proper Study, Oxford: Clarendon.

Kessler, G.

1980 Frege, Mill and the Foundations of Arithmetic, Journal of Philosophy, LXXVII, 65-79.

LAVINE, S.

1994 Understanding the Infinite, Cambridge MA: Harvard University Press.

Leisenring, A.C.

1969 Mathematical Logic and Hilbert's Epsilon Symbol, London: Macdonald.

LEWIS, D.K.

1991 Parts of Classes, Oxford: Blackwell.

MADDY, P.

1990a Physicalistic Platonism, in Irvine, A.D. (ed.), Physicalism in Mathematics, Dordrecht: Kluwer.

MADDY, P.

1990b Realism in Mathematics, Oxford: Clarendon.

MADDY, P.

1997 Naturalism in Mathematics, Oxford: Clarendon. 
MADDY, P.

2000 Does Mathematics need New Axioms?, The Bulletin of Symbolic Logic, 6.4, 413-422.

MAYBERRY, J.P.

2000 The Foundations of Mathematics in the Theory of Sets, Cambridge: C.U.P.

MYCIELSKI, J.

1981 Analysis without Actual Infinity, Journal of Symbolic Logic, 46.3, 625-633.

Quine, W.V.O.

1963 Set Theory and its Logic, Cambridge MA: Belknap Press.

RODYCH, V.

2000 Wittgenstein's Critique of Set Theory, The Southern Journal of Philosophy, XXXVIII, 281-319.

RYLE, G.

1973 The Concept of Mind, Harmondsworth: Penguin.

Simons, P.

1982 Against the Aggregate Theory of Number, Journal of Philosophy, LXXIX, 163-167

SLATER, B.H.

2000 Concept and Object in Frege, Minerva, 4.. See:

http://www.ul.ie/\%7Ephilos/vol4/frege.html

Tiles, M.

1989 The Philosophy of Set Theory, Oxford: Blackwell.

Wright, C.

1983 Frege's Conception of Numbers as Objects, Aberdeen: Aberdeen University Press. 